\title{
A CONTRIBUIÇÃO DE JASPERS, BINSWANGER, BOSS E TATOSSIAN PARA A PSICOPATOLOGIA FENOMENOLÓGICA
}

\author{
The Contribution of Jaspers, Binswanger, Boss and Tatossian to Phenomenological Psychopathology \\ La Contribución de Jaspers, Binswanger, Boss y Tatossian para la Psicopatología Fenomenológica
}

VIRGÍNIA MOREIRA

\begin{abstract}
Resumo: Este artigo tem como objetivo discutir as contribuições de quatro grandes nomes da tradição da Psicopatologia Fenomenológica: Karl Jaspers, que através de um método descritivo-compreensivo fundou a psicopatologia enquanto área específica do conhecimento com sua Psicopatologia Geral; Ludwig Binswanger, o criador da Psicopatologia Fenomenológica; Medard Boss que se propôs a desenvolver uma psicopatologia de inspiração Daseinsanalítica e, finalmente, Arthur Tatossian que desenvolve uma psicopatologia do Lebenswelt (mundo vivido).
\end{abstract}

Palavras-chave: Psicopatologia fenomenológica; Jaspers; Binswanger; Boss; Tatossian.

\begin{abstract}
This article aims to discuss the contributions of four big names of the Phenomenological Psychopathology tradition: Karl Jaspers, whom through a descriptive comprehensive method funded psychopathology as an specific area of knowledge with his General Psychopathology; Ludwig Binswanger, the creator of the Phenomenological Psychopathology; Medard Boss whom tried to develop a psychopathology from a Daseinsanalytic inspiration, and finally, Arthur Tatossian, whom develops a psychopathology of the Lebenswelt (lived world).

Keywords: Phenomenological psychopathology; Jaspers; Binswanger; Boss; Tatossian.

Resumen: Este artículo tiene como objetivo discutir las contribuciones de cuatro grandes nombres de la tradición de la Psicopatología Fenomenológica: Karl Jaspers, que a través de un método descriptivo comprensivo ha fundado la psicopatología en cuanto área específica del conocimiento con su Psicopatología General; Ludwig Binswanger, el creador de la Psicopatología Fenomenológica; Medard Boss que se ha propuesto a desarrollar una psicopatología de inspiración Daseinanalítica y, finalmente, Arthur Tatossian que desarrolla una psicopatología del Lebenswelt (mundo vivido).

Palabras-clave: Psicopatología psicopatológica; Jaspers; Binswanger; Boss; Tatossian.
\end{abstract}

\section{Introdução}

Psicopatologia [de psic(o)- + patologia.] se define como patologia das doenças mentais ou como o estudo das causas e natureza das doenças mentais. Psic(o) - vem do grego - psyché - que significa alento, sopro de vida, alma. Patologia, afecção, dor, pato, que também provém do grego - pathos - que significa "doença, paixão, sentimento". Ambos os termos foram introduzidos na linguagem científica internacional a partir do século XIX (Cunha, 1997).

O primeiro registro de utilização do termo psicopatologia foi na Alemanha em 1878, com Emminghaus, mas, neste momento, psicopatologia equivalia à psiquiatria clínica. Enquanto método e disciplina, a psicopatologia nasce no início do século XX, na França, com o filósofo Theodule Ribot e a criação do método psicopatológico enquanto psicologia patológica, um ramo da psicologia científica diferente da psicologia experimental ou genéo tica (Bauchesne, 1993). A substituição do termo psicolo-

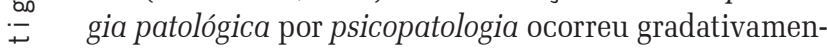
$\stackrel{\text { t }}{\longleftarrow}$ te, correspondendo a um deslizamento de sentido, que se deu quando a psicologia patológica se propôs a ser uma psicologia da conduta, substituindo, paulatinamente, a linguagem das ações nervosas por uma linguagem psicológica (Widlöcher, 1996; Moreira, 2002).

Em 1913, na Alemanha, com a publicação de Psicopatologia Geral de Karl Jaspers, nasce a psicopatologia propriamente dita, representando uma corrente diferenciada em relação à vertente de Ribot, que se desenvolverá como uma psicopatologia fenomenológica. Este artigo tem como objetivo discutir as contribuições singulares de Karl Jaspers, Ludwig Binswanger, Medard Boss e Arthur Tatossian ao desenvolvimento da tradição da psicopatologia fenomenológica.

\section{Karl Jaspers e uma Psicopatologia Descritivo- Compreensiva}

Karl Jaspers (1883-1902), médico psiquiatra alemão, foi também professor de filosofia na Universidade de Heidelberg. Seu pensamento está assim imbuído, desde sua origem, de seu interesse em reunir as ciências na- 
turais e as ciências humanas, caminho sobre o qual ele desenvolverá a psicopatologia. Isto foi possível a partir da situação privilegiada de Jaspers, como filósofo, dispor para a fundamentação de suas idéias, dos elementos empíricos acessíveis na Clinica Psiquiátrica de Heildelberg (Rodrigues, 2005).

A publicação de Psicopatologia Geral, em 1913, marca o início da psicopatologia enquanto campo específico do saber, diferenciado da psiquiatria. A proposta de Jaspers era integrar o modelo causalista-explicativo empregado pelas ciências naturais, ao modelo histórico-compreensivo, próprio das ciências humanas, para a descrição e compreensão do fenômeno psíquico. O que conferiu valor central a esta obra foi, especialmente, sua crítica metodológica e sistematização dos dados. Sua tarefa foi mapear suportes conceituais e métodos vigentes pelo exame de suas virtudes e limitações na sua aplicação individual, isto é, a partir da descrição e compreensão de casos individuais, Jaspers propôs um modelo de psicopatologia geral, que na sua visão, poderia atender às aspirações científicas (Rodrigues, 2005). Nas palavras de Jaspers, na introdução de Psicopatologia Geral:

A prática da profissão psiquiátrica se ocupa sempre do indivíduo humano todo (...). Aqui, todo o trabalho se relaciona com um caso particular. Não obstante, para satisfazer as exigências decorrentes dos casos particulares, o psiquiatra lança mão, como psicopatólogo, de conceitos e princípios gerais (Jaspers, 1913/1987, p. 11).

A psiquiatria de sua época era entendida como parte das ciências naturais, utilizando, unicamente, o modelo explicativo-causal para compreender os fenômenos objetivos. Com o objetivo de associar este modelo ao modelo histórico-compreensivo, Jaspers introduz em Psicopatologia Geral o método fenomenológico, que se tornou então, a grande "novidade" do seu pensamento no âmbito da psiquiatria. Este fato gera, até os dias de hoje, muitos mal-entendidos no sentido de nomear o trabalho de Jaspers como psicopatologia fenomenológica, quando ele mesmo deixa muito claro que a fenomenologia é apenas um dos métodos possíveis para a psicopatologia. No prefácio da sétima edição de 1959 esclarece:

Se, (...) o meu livro é por vezes designado como representante da corrente fenomenológica ou da corrente de psicologia compreensiva, só em parte esta designação é correta, uma vez que o seu sentido é mais compreensivo: a saber o esclarecimento dos métodos da psiquiatria em geral, de seus modos de concepção e de seus caminhos de investigação (Jaspers, 1913/1987, p. 7).

Ou seja, Jaspers entende seu método como compreensivo, não como fenomenológico, indicando com isto que a compreensão inclui tanto o método fenomenológico (que para ele será prioritariamente a descrição), como o tradicional método explicativo-causal.

\subsection{A Psicopatologia como uma Ciência}

Para Jaspers (1913/1987), a psiquiatria, como uma profissão prática, se volta para os casos individuais enquanto que a psicopatologia, como uma ciência, se desenvolve no domínio dos conceitos e das regras gerais, isto é, sobre os modos das experiências, buscando seu sentido geral:

O objeto da psicopatologia é o acontecer psíquico realmente consciente. Queremos saber o que os homens vivenciam e como o fazem. Pretendemos conhecer a envergadura das realidades psíquicas. E não queremos investigar apenas as vivências humanas em si mas também as condições e causas de que dependem os nexos em que se estruturam, as relações em que se encontram e os modos em que, de alguma maneira, se exteriorizam objetivamente (Jaspers, 1913/1987, p. 13).

O tema da Psicopatologia Geral de Jaspers é o homem todo em sua enfermidade psíquica ou psiquicamente determinada. O homem se diferencia do animal e ocupa um lugar especial, pois o espírito e a alma atuam sobre as enfermidades psíquicas. A alma, por sua vez, tornase objetiva pelo que é perceptível no mundo: fenômenos somáticos, expressões, comportamentos e ações, bem como na linguagem.

Para Jaspers (1913/1987), a consciência se caracteriza como consciência objetiva, como interioridade real de uma vivência, como auto-reflexão e consciência de si mesmo, como intencionalidade do sujeito e como o todo da vida psíquica momentânea. A noção de inconsciente, encontrada em "Psicopatologia Geral", refere-se ao não lembrado, o que não está relacionado com a atenção, o que é inadvertido, o que dá origem. A atenção é definida neste contexto como consciência clara, onde se dá a vivência do voltar-se para um objeto. A seleção de conteúdos conscientes e o afeto sobre o curso da vida psíquica condicionam a claridade da consciência de uma vivência.

As noções de percepção, enquanto conhecimento e reconhecimento de um dado fenômeno, e de orientação, como rendimento apreensivo mais complexo, serão também fundamentais à psicopatologia fenomenológica de Jaspers, compreendida por ele como fenomenológica por investigar o fenômeno subjetivamente: o psíquico expressa o mundo do paciente através de seu funcionamento, suas manifestações e ações (Moreira, 2002)

Ainda para Jaspers (1913/1987), no seu propósito de construção de uma psicopatologia científica, a compreensão do fenômeno psicopatológico pode ser estática, genética (contextualizada) ou total, o que implica na consti- 
tuição do indivíduo, abordando a unidade da doença e a totalidade biográfica. Sua psicopatologia geral distingue quatro grupos de fatos a serem estudados: os fenômenos vividos (consciência), o rendimento objetivo (apreensão, memória e inteligência), os fenômenos somáticos e as objetividades de sentido (estruturas de percepção). Na perspectiva destes fenômenos, a expressão dos pacientes com relação aos seus sintomas se dá pela descrição do espaço e tempo e a consciência do corpo e da realidade (Moreira, 2002).

\subsection{A Introdução do Método Fenomenológico}

Embora Psicopatologia Geral seja a fonte mais difundida do método fenomenológico de Jaspers, neste livro ele está descrito de maneira sucinta. O foco maior é sobre a descrição fenomenológica das experiências específicas sem oferecer maiores detalhes do método. É em um trabalho menos conhecido, de 1912 - intitulado "A abordagem fenomenológica em psicopatologia" - que a fundamentação, a descrição e a aplicação do método fenomenológico são mais detalhadas (Rodrigues, 2005).

No artigo de 1912, Jaspers observa que ao se examinar um paciente psiquiátrico é comum a distinção entre sintomas objetivos e subjetivos. Os sintomas objetivos são aqueles "mensuráveis", que podem ser percebidos pelos sentidos tais como movimentos registráveis, a fisionomia do indíviduo, sua atividade motora, expressão verbal, ações e conduta em geral, que podem incluir idéias delirantes ou falsas memórias etc. Ou seja, os sintomas objetivos são todos os conteúdos racionais comunicados pelo paciente sem o auxílio de qualquer "empatia" para com o mesmo.

No entanto, lembra Jaspers (1912/2005), existem os sintomas subjetivos que, para serem compreendidos, exigem um processo subjetivo de "transposição de si mesmo, por assim dizer, ao psiquismo do outro indivíduo; isto é, pela empatia” (p. 770). Os sintomas subjetivos incluem as emoções como alegria, medo, tristeza: processos mentais que necessitam ser inferidos a partir das manifestações do paciente e que por isso, são considerados pouco confiáveis do ponto de vista científico. Trata-se da priorização de uma "psicologia científica" em detrimento de uma "psicologia subjetiva”. É esta posição tradicional que Jaspers (1912/2005) critica: "Enquanto a psicologia objetiva, eliminando tudo aquilo que é psíquico, se converte em fisiologia, a psicologia subjetiva ambiciona preservar a dita vida psíquica como objeto de seu estudo" (p. 771).

Tendo em vista a diversidade de fenômenos psíquicos existentes, Jaspers (1912/2005) assinala que, para se abordar questões subjetivas, é necessário tornar claro qual é a experiência psíquica específica referida a diferentes fenômenos psíquicos, identificando semelhanças e diferenças entre estes:
Este trabalho preliminar de representação, definição e classificação dos fenômenos, perseguido como atividade independente, constitui a fenomenologia (...). Na esfera da investigação psicológica E. Husserl deu o primeiro passo crucial em direção a uma fenomenologia sistemática, seus antecessores antes nisto havendo sido Brentano e sua escola, assim como Th. Lipps (Jaspers, 1912/2005, p. 772).

Para desenvolver o seu método fenomenológico na psicopatologia, Jaspers toma como base o primeiro Husserl - o da "psicologia descritiva" (nesta fase, ainda muito próximo do pensamento de Brentano) - que foi interpretado por ele como uma fenomenologia descritiva. Mas como bem assinala Rodrigues (2005), reconhecer que a fenomenologia de Jaspers é uma fenomenologia descritiva não deve se dar no sentido pejorativo, como acontece freqüentemente por parte de seus críticos. Jaspers se restringe à etapa descritiva como a etapa inicial para que se possa atingir o fenômeno subjetivo. Seu objetivo era garantir a cientificidade da compreensão dos sintomas subjetivos.

Assim, a fenomenologia surge, para ele, como um método visado para responder às necessidades de cientificidade para a psico(pato)logia e, ao mesmo tempo, atender ao imperativo de não exclusão ao verdadeiro objeto de estudo destas disciplinas: a experiência subjetiva (Rodrigues, 2005, p. 764).

Ainda que Karl Jaspers não deva ser considerado o iniciador da Psicopatologia Fenomenológica - um mal entendido comum em nossos dias - cabe a ele, sem dúvida, o papel pioneiro de se preocupar com cientificidade do sintoma subjetivo. Foi esta preocupação que fez com que ele buscasse na fenomenologia do primeiro Husserl um método que pudesse compreender cientificamente o sintoma subjetivo. Assim, deve-se reconhecer que a fenomenologia de Jaspers não pode ser chamada de psicopatologia fenomenológica, justamente por sua concepção restritiva da experiência científica ligada ao dualismo cartesiano da psique e do soma (Tatossian, 2006). Mas, como assinala Fédida (1998), "a psicopatologia geral de Karl Jaspers, pouco rigorosa fenomenologicamente, tem o mérito de contribuir historicamente para a constituição de uma antropologia fenomenológica em psicopatologia” (p. 109). É possível afirmar que em Jaspers se encontram os germes da psicopatologia fenomenológica desenvolvida posteriormente em Binswanger e toda a tradição da psicopatologia fenomenológica até os dias atuais.

Enquanto um campo específico do saber científico que se funda na interseção da tradição histórico-compreensiva das ciências humanas com a tradição explicativo-causal das ciências naturais, a psicopatologia deve a Jaspers não apenas a sua origem, mas seu desenvolvimento conturbado, sempre envolvido pela discussão da 
subjetividade versus objetividade, que se mantém ainda em seu bojo na contemporaneidade.

\section{Ludwig Binswanger: Uma Psicopatologia Fenome- nológica}

Ludwig Binswanger (1881-1966), médico suíço com formação psiquiátrica junto a Bleuer e a Jung, no Hospital Burghölzli, foi diretor do Sanatório Bellevue, fundado por seu avô, em Kreuzlingen, na Suiça. Iniciou sua carreira aderindo à proposta clínica psicanalítica, mas foi gradualmente se afastando das proposições metapsicológicas de Freud, à medida em que seus estudos da fenomenologia de Husserl e da ontologia fundamental de Heidegger iam se aprofundando (Pereira, 2001). No seu texto "Analyse Existentielle et Psychothérapie”, Binswanger retoma uma comunicação feita no Congresso Internacional de Psicoterapia em Barcelona em 1958, em que deixa clara sua divergência em relação à psicanálise:

Apesar de toda a nossa admiração pela obra de Freud e toda a estima pela importância gigantesca da psicanálise no plano da psicoterapia, nossa formação filosófica não nos permitiu reconhecer suas hipóteses filosóficas, particularmente no que concerne à relação entre corpo e alma, entre o instinto e o espírito (Binswanger 1971c, p. 155).

Ao contrário da psicanálise, que havia sido criada por Freud a partir de uma preocupação terapêutica, a análise existencial de Binswanger teria sido inicialmente um novo método de pesquisa, que pretendia se contrapor ao da psiquiatria tradicional: "A direção de pesquisa analítico existencial em psiquiatria surgiu da insatisfação quanto aos projetos de compreensão científica da psiquiatria da época” (Binswanger 1970, p. 115). Isto explica o caráter mais completo e elaborado da psicopatologia decorrente da análise existencial binswangeriana do que suas teorizações sobre a psicoterapia propriamente dita, tendo em vista que só secundariamente ela teria se organizado como proposta de tratamento. A Daseinsanalyse de Binswanger instituiu um corte na tradição médica e psiquiátrica da psicopatologia (Pereira, 2001).

\subsection{A Psicopatologia como um Campo Diferenciado do Saber}

Na perspectiva de sua Daseinanalyse e de sua antropologia fenomenológica Binswanger (1971b) defendeu a idéia - já defendida anteriormente por Jaspers, embora sobre outras bases - de se especificar a psicopatologia em um campo diferente do das ciências naturais, que entendiam o homem como um sistema de funções de ordem orgânica ligadas a processos naturais no tempo. Sua pro- posta da antropologia fenomenológica deveria ser a disciplina para fundar a psicopatologia e a psiquiatria tendo em vista que "vê nele [o homem] um ser pessoal que vive sua vida e cuja continuidade - não somente vivida, mas se vivendo, ela mesma - se desdobra em história” (Kuhn \& Maldiney 1971, p, 12).

No seu famoso texto Fonction vitale et histoire intérieure, publicado em Introduction a l'Analyse Existentiele, Binswanger (1971b) reconhece a contribuição metodológica de Jaspers em relação à distinção entre relações de causalidade e de compreensão no campo do acontecer psíquico. As relações causais se referem aos fatos concretos que estabelecem conjunções constantes com o surgimento de certos quadros mentais. As relações de compreensão visam a dar conta do encadeamento psíquico de uma forma compreensível para nós. "E nós já assinalamos repetidas vezes que não podemos nos apoiar nem em um conceito de valor causal de um lado, nem, por outro lado, naquele da compreensão" (Binswanger, 1971b, p. 55-56). Buscando a superação desta discussão que remete à dualidade físico x psíquico:

Binswanger propõe que se examine, em seu lugar, a questão mais fundamental: aquela do Ser e das relações do fenômeno psicopatológico com a existência do que padece. Dessa forma a análise existencial abriria a possibilidade de um olhar sobre a totalidade da existência do homem. A dimensão histórica, anteriormente evocada, é decisiva no pensamento binswangeriano, na medida em que se apóia na $D a-$ seinsalytik de Heidegger para construir suas próprias bases teóricas e metodológicas de abordagem da psicopatologia (Pereira 2001, p. 139).

\subsection{A Analítica do Dasein de Heidegger na Psicopato- logia Binswangeriana}

É por partir da Análise do Dasein heideggeriana que na Daseinsanalyse de Binswanger os conceitos de temporalidade e espacialidade terão um lugar de destaque. As dimensões fundamentais constituintes do Dasein os existenciais descritos por Heidegger em Ser e Tempo - são a temporalidade, a espacialidade, o ser-com-o-outro, a disposição, a compreensão, o cuidado (Sorge), a queda e o ser-para-a-morte (Moreira, 2010). No seu texto "Analyse existentielle et psychotherapie", Binswanger (1971d) esclarece que:

Ainda que Heidegger tenha sido para nós o pensador mais prestigiado de nossos tempos, e que ano a ano mergulhemos mais fundo no coração de sua obra, nosso propósito pessoal não era de estudá-la como tal, mas de retirar dela o que seria útil à psiquiatria, cujo fundamento e aprofundamento filosófico sempre haviam sido objeto de nossas preocupações (p. 156). 
É importante observar que a apropriação que Binswanger faz da Daseinanlyse de Heidegger para aplicá-la à sua Daseisnanalyse no campo da psicopatologia, utilizando-se do método fenomenológico, não se restringe apenas a descrever as vivências dos doentes e seus encadeamentos psíquicos ou naturais que levaram ao surgimento da doença, como o faz Jaspers, mas apreender as condições particulares de existência de um indivíduo singular em relação aos existenciais descritos por Heidegger no plano ontológico.

O método psicopatológico de Binswanger visa descrever a experiência de mundo e as condições de existência tal como estas se dão nas condições particulares do Dasein. Trata-se de uma abordagem fenomenológica, no sentido em que depende da abertura à experiência concreta do outro, mas, ao mesmo tempo, volta-se às estruturas a priori e transcendentais da existência, visando situar a organização específica daquele indivíduo enquanto Dasein, face a seus existenciais. Trata-se, portanto, de descrever o mundo a partir da perspectiva e das possibilidades daquela existência singular (Pereira 2001, p, 140).

\subsection{Umwelt, Mitwelt e Eigenwelt}

Em um de seus primeiros escritos - Grundformen und Erkenntnis menschlichen Daseins ("Formas fundamentais e conhecimento da existência humana”), publicado em 1942 -, Binswanger descreve modos simultâneos de ser no mundo de seus pacientes, distinguindo três regiões do mundo: Umwelt, Mitwelt e Eigenwelt. Ainda que os escritos posteriores de Binswanger tenham ampliado suas análises para modos existenciais de ser no mundo, esta definição dos três modos de ser no mundo passou a ser bastante conhecida e associada ao nome de Binswanger, tanto como por conta dele ter utilizado estes três modos de ser no mundo para analisar seu conhecido caso de Ellen West (Binswanger, 1977), como pelo fato desta definição ter sido utilizada e divulgada por Rollo May, nos Estados Unidos. Em seu livro A Descoberta do Ser, Rollo May (1988) resume os três modos de ser-no-mundo de Binswanger.

O primeiro modo é o Umwelt, que significa literalmente "o mundo ao redor". É o mundo natural, o mundo biológico, conhecido por ambiente. O Umwelt é o mundo material, que cerca a todos os animais e seres humanos, abrangendo necessidades biológicas, impulsos e instinto. É o mundo dos ciclos naturais do dormir e acordar, do nascer e morrer, o mundo que é imposto a cada um nós pelo nascimento. $\mathrm{O}$ segundo modo - o Mitwelt - é o mundo dos inter-relacionamentos, o mundo com o outro, que caracteriza o humano. Os animais vivem apenas no Umwelt. O ser humano não existe senão no Mitwelt, que é a característica básica do Dasein: ser-no-mundo. Podese dizer que os animais têm um ambiente, enquanto que os seres humanos têm um mundo, que envolve suas re- lações com os outros indivíduos, com a família e a comunidade. O Mitwelt é o modo de ser no mundo social. Finalmente, o terceiro modo - o Eigenwelt é o "mundo próprio", o "eu", que inclui um corpo. O Eigenwelt pressupõe uma autoconsciência, uma percepção de si mesmo, um "auto-relacionamento" que também está presente apenas nos seres humanos. Não se trata de uma experiência meramente subjetiva, ao contrário, é a base sobre a qual nos relacionamos a partir da percepção do que uma coisa qualquer no mundo significa para mim.

Binswanger estava preocupado em descobrir a visão de mundo de seus pacientes, o mundo vivido de cada um. Neste sentido é que considerou importante, na clínica, que envolve principalmente a relação intersubjetiva médico-paciente, observar como o paciente vivencia cada uma dessas dimensões de ser-no-mundo. Ainda que Umwelt, Mitwelt e Eigenwelt sejam três regiões de mundo diferentes, eles serão sempre modos simultâneos de ser-no-mundo.

\subsection{Método Fenomenológico x Método Psicopatológico}

No seu texto "De la Phénomenologie", Binswanger (1971c) discute as diferenças metodológicas entre a fenomenologia e a psicopatologia, lembrando que a pesquisa fenomenológica das essências é diferente da busca dos fatos patológicos:

Desde que a psicopatologia é e será sempre uma ciência da experiência ou dos fatos, ele não quererá nem poderá jamais aceder em uma generalidade absoluta, a uma intuição das essências puras (...). Entendemos, por outro lado que não é insensato falar de uma fenomenologia psicopatológica, apesar desta profunda diferença entre a pesquisa dos fatos psicopatológicos e a pesquisa fenomenológica das essências (p. 101).

Binswanger (1971c) adverte que, se por um lado uma fenomenologia psicopatológica não pode buscar as essências, por outro é importante que não se cometa o engano de realizar uma psicopatologia meramente descritiva ou subjetiva. Uma fenomenologia psicopatológica busca o sentido, a significação da palavra, a experiência vivida. Busca se introduzir "dentro" em lugar de julgar "sobre" a significação da palavra, tal como longamente explicado no seu conhecido exemplo do paciente com alucinação que ao ser perguntado se ele estaria escutando vozes, responde: "Não, eu não escuto vozes, mas à noite as salas-de-falar estão abertas e que elas fossem dispensadas eu gostaria”. Ao descrever as longas conversas com este paciente, o psiquiatra suíço mostra que, no fenômeno particular, a pessoa se faz conhecer e, inversamente, é o fenômeno que faz o psicoterapeuta penetrar na pessoa. 
Do ponto de vista do fenomenólogo, o essencial de tais fenômenos psicopatológicos reside em que você não vê jamais um fenômeno isolado, mas aquele que se desenrola sobre um plano de fundo de um Eu, de uma pessoa, ou, dito de outra forma, nós o vemos sempre como expressão ou manifestação emanando de tal ou tal pessoa (Binswanger, 1971c, p. 105).

E mais adiante no mesmo texto:

O fenomenólogo, analisando a experiência psicopatológica vivida, (...) busca se familiarizar com as significações que a expressão verbal do doente despertam nele (...). No lugar de refletir sobre sua relação com outros fenômenos psíquicos anormais e suas condições de aparição, ele busca apenas os sinais distintivos imanentes a esta experiência psicopatológica e o que se pode descobrir nela (Binswanger, 1971c, p. 116).

\subsection{A Psicopatologia Fenomenológica}

A partir deste arcabouço teórico e metodológico é que, na introdução do seu livro Introduction a l'Analyse Existentielle, Binswanger (1971a) afirma que "o ser-psiquiatra depende referencialmente do encontro e da compreensão mútua com o outro tomado em sua totalidade e ele está dirigido à compreensão do homem em sua totalidade (...)” (p. 47). Nesse sentido, entende que a psiquiatria é uma ciência do homem, da presença humana, cuja missão enquanto ciência é discriminar o que se aplica ao doente ou ao sadio e buscar a maneira como a presença do doente pode ser modificada em uma presença sadia. Assim, "o pro-jeto científico da psiquiatria não é mais 'a psyché doente', e seus 'transtornos funcionais', nem tão pouco se trata mais 'do doente do espírito' com suas anomalias de comportamento, mas 'do homem”' (Binswanger 1971d, p. 157).

A psicopatologia deve ser entendida como o que se afasta da estrutura apriorística do ser em suas categorias ontológicas. A presença perturbada se caracteriza como o extravio ou o malogro da sua realização ontológica, de maneira que uma só categoria passa a servir de "fio condutor" do projeto de mundo (May, 1988). A presença fica limitada em torno de uma categoria existencial prioritária (os chamados existenciais de Heidegger). Por exemplo, quando a presença fica limitada em torno da corporalidade, temos o Dasein hipocondríaco ou o bulímico; na temporalidade temos o melancólico ou o maníaco (Tatossian, 2006); na espacialidade encontramos o agorafóbico, e assim por diante. Ocorre aí o que Binswanger vai chamar de formas de existência frustrada, onde o indivíduo se fecha em si mesmo perdendo o eixo comum com o mundo do outro. A presença psicopatológica se projeta assim de diferentes formas: presença perdida (melancolias), momentânea (manias), vazia (es- quizofrenias), exibicionista (histeria) e controlada (transtorno obsessivo-compulsivo).

Ainda que o Dasein seja um conceito fundamental na teoria da psicopatologia e da psicoterapia de Binswanger, e ele se utilize amplamente do pensamento de Heidegger em seus livros, seu pensamento permanece mais próximo do de Husserl do que do de Heidegger (Loparic, 2002; Tatossian; 2006, Freire, 2008; Gonçalves, Garcia, Dantas \& Ewald, 2008; Mattar \& Novaes de Sá, 2008; Moreira, 2010). O proprio Heidegger (2001), no seminário de 23 de novembro de 1965, em Zollikon, na Suíca explicita: "A fenomenologia de Husserl, que ainda o influencia [Binswanger], a qual permanece fenomenologia da consciência, impede a visão clara da hermenêutica fenomenológica do Dasein" (Heidegger 2001, p. 146). Binswanger reconheceu este fato, o que o levou a propor, por ocasião do I Congresso de Psiquiatria, em 1950, em Paris, a ideia de uma "Análise Antropológica-Fenomenológica". Esta denominação não chegou a ser amplamente utilizada e foi, finalmente, sob a denominação "Análise existencial" que seu trabalho passou a ser divulgado nos últimos anos, agora com a sua concordância que, no mesmo congresso, de 1950, fora negada por não querer que sua proposta fosse associada com o pensamento de Sartre (Verdeaux \& Kuhn, 1971).

Para além das várias denominações assumidas pela extensa obra de Binswanger - Dasinsanalyse, Análise Antropológica-Fenomenológica, Análise Existencial -, no âmbito da psicopatologia sua contribuição fenomenológica foi de tal magnitude que Binswanger passou a ser considerado o "pai da psicopatologia fenomenológica" (Van den Berg, 1994; Moreira, 2010).

\section{Medard Boss: Uma Psicopatologia de Inspiração Daseinsanalítica}

Medard Boss (1903-1990), médico psiquiatra também suíço, foi analisado por Freud e influenciado por Bleuler, com quem trabalhou por quatro anos no Hospital Burghölzli. Quando estudou em Berlim teve professores do círculo de Freud, como Karen Horney e Kurt Goldstein. Foi, também, sócio de Jung, que propunha uma psicanálise diferente da proposta freudiana.

No prefácio à primeira edição dos Seminários de Zollikon, de Martin Heidegger, editado por Boss (1976), este descreve seu encontro com Heidegger. Conta que, quando serviu na guerra, pela primeira vez em sua vida ficara entediado: “Aquilo que chamamos 'tempo' tornouse problemático. Comecei a refletir sobre essa 'coisa'. Procurei ajuda em toda a literatura a esse respeito a que tive acesso. Por acaso encontrei num jornal uma nota sobre o livro Ser e Tempo, de Martin Heidegger” (p. 10).

Neste prefácio, Boss relata o quanto lhe parecera difícil e intrigante, a leitura da obra de Heidegger, tendo em vista sua formação científico-médica. De forma que, 
ainda que houvesse sido desestimulado por colegas que designavam a Heidegger de nazista (que Boss argumenta serem calúnias), em 1947 entrou em contato por carta com Heidegger de quem se tornou amigo pessoal, se correspondendo ao longo de cerca de 30 anos.

Durante dez anos, a partir de 1959, Boss deu início à coordenação de uma série de seminários ministrados por Heidegger em sua casa em Zollikon, na Suíça, para cerca de 70 psiquiatras e estudantes de psiquiatria. Estes seminários tornaram-se famosos nos meios psiquiátrico e psicológico clínico, pois se constituiu em momento único em que Heidegger mais profundamente descreve sua Analítica do Dasein para um público de psiquiatras, e não de filósofos (o que, conta Boss, era de interesse de Heidegger que visava a um maior público que o filosófico). Estes seminários, bem como as cartas trocadas entre Medard Boss e Martin Heidegger foram publicados no livro Seminários de Zollikon, cuja edição em português, em 1976, se deveu à iniciativa do médico e psicoterapeuta brasileiro, Solon Spanoudis, quem, por sua vez, trocara cartas com Boss convidando-o a participar de alguns seminários no Brasil, a partir de 1973.

É interessante observar como a origem da Daseinsanalyse de Boss se diferencia da de Binswanger, no sentido de que o que moveu Boss ao encontro com Heidegger foi um interesse pessoal e não teórico, a partir de sua própria vivência de tédio durante a guerra (tema sobre o qual Heidegger escrevera). Enquanto Binswanger foi antes de tudo levado a penetrar no pensamento desse filósofo por um ‘impulso puramente científico’ e não, como Freud, por um interesse de ordem terapêutica, foram sobretudo preocupações terapêuticas que determinaram a escolha de Boss. Esperava em primeiro lugar que as recentes considerações filosóficas de Heidegger lhe fossem úteis no domínio da terapêutica (Boss \& Condrau 1997, p. 26). O artigo de autoria de Boss, publicado em 1997 na Revista da Associação Brasileira de Daseinsanalyse, onde ele faz uma apresentação pessoal da Analítica do Dasein de Heidegger é intitulado "Encontro com Boss" (Boss, 1997).

\subsection{A Daseinsanalyse de Boss}

Descontente com os fundamentos da psiquiatria tradicional e, de início, estimulado pelos trabalhos de Binswanger, Boss se voltou para o pensamento de Heidegger, desenvolvendo todo o seu trabalho, ao longo dos anos que se seguiram, em torno da sua Analítica do Dasein. Acreditava que a psicopatologia muito se enriqueceria por um pensamento que não permitia a colocação da distinção cartesiana sujeito-objeto e que, por outro lado, aproximava a medicina da psicologia. Por isso considerava que a Daseinsanalyse não deveria ser considerada simplesmente mais uma escola: "É, antes de tudo e primordialmente uma nova abordagem do conjunto dos fe- nômenos normais e patológicos do existir humano (...) tem como intuito ver sem deformações aquilo que se mostra a nós do si-mesmo" (Boss \& Condrau, 1997, p. 26).

A concepção Daseinanalítica de Boss parte da observação de que o homem nunca se encontrou primordialmente sozinho, subsistindo sozinho; o homem pode se relacionar de diferentes modos, mas não pode não se relacionar; mesmo a indiferença é um modo de relação; os homens estão sempre e primordialmente co-existindo perto das mesmas coisas de um mesmo mundo, contribuindo primariamente em comum, embora cada um a seu modo, para manter aberto este mundo, o que se constitui no caráter fundamental de ser-com-o-outro primordial (Boss \& Condrau, 1997). Ou seja, o existencial ser-como-outro é central, ainda que Boss também dê atenção aos outros existenciais descritos por Heidegger tais como a temporalidade, a espacialidade, a disposição, o cuidado (Sorge), a queda e o ser para a morte. Boss retoma assim, o mais ao "pé da letra” possível, as idéias de Heidegger em Ser e Tempo, onde o grande filósofo distingue, no Dasein, os planos ôntico (plano relacionado à elucidação da existência do Dasein) e ontológico, que é a apresentação das estruturas existenciais do ser, dimensões fundamentais constituintes do Dasein que Heidegger chamará de "existenciais". O ôntico se refere ao ente, enquanto o ontológico diz respeito ao ser (Heidegger, 1989).

Com base no existencial ser-com-o-outro a Daseinsanalytik de Heidegger, retomada por Boss, entende a existência humana como uma abertura estendida e transparente, tanto no sentido temporal quanto espacial, para tudo aquilo que vem ao seu encontro no mundo. A essência do existir humano é ser esta "clareira”, que consiste meramente em um poder "ver", experienciar, o que vem ao seu encontro (Heidegger, 1989).

\subsection{A Inspiração Daseinsanalítica na Psicopatologia}

Ao contrário de Binswanger, Boss nunca chegou (nem, aparentemente era esta sua intenção) a propor uma teoria de psicopatologia. No entanto, parece possível dizer que seus escritos, particularmente o artigo Análise Existencial - Daseinsanalyse: como a daseinsanalyse entrou na psiquiatria, escrito em co-autoria com seu assistente G. Condrau, a partir do qual desenvolvemos este tópico neste artigo, mostram que ele realizou curtos "ensaios" do que poderia vir a ser chamado uma "psicopatologia de inspiração daseinsanalítica”. Nesta perspectiva, "o modo de ser-doente só pode ser compreendido a partir do modo de ser-sadio e da constituição fundamental do homem normal, não perturbado, pois todo modo de ser-doente representa um aspecto particular de determinado modo de ser-são" (Boss \& Condrau 1997, p. 29). Na medida em que entende que a essência fundamental do homem sadio caracteriza-se por suas possibilidades de relação na abertura livre de seu mundo - a "clareira" - o 
modo de ser-doente poderá ser compreendido como uma limitação dessas possibilidades.

Boss \& Condrau (1997) subdividem o modo de ser-doente em: 1) Ser doente caracterizado por uma perturbação evidente da corporeidade do existir humano; 2) Serdoente caracterizado por uma perturbação pronunciada da espacialidade do seu ser-no-mundo; 3) Modo do serdoente caracterizado por uma limitação da disposição própria à essência da pessoa; e 4) Modos de ser-doente concernentes a limitações na realização do ser-aberto e da liberdade. Ainda que cada um destes modos de ser-doente faça referência a um existencial específico do Dasein, descrito em Ser e Tempo enquanto dimensões fundamentais do ser-aí, formam, todos juntos, uma estrutura total e indivisível. Assim, se um deles é perturbado em sua realização, as outras dimensões, como parte do todo, sofrerão igualmente as conseqüências.

Esta questão é esclarecida por Boss \& Condrau (1997) com um exemplo sobre o primeiro modo de ser-doente, relativo à corporeidade do existir humano:

(..) qualquer modo da corporeidade faz parte a tal ponto e tão diretamente do ser-no-mundo do homem, isto é, de sua existência, que qualquer redução toca sempre e imediatamente este ser-no-mundo e, por isso mesmo, todas as suas possibilidades de relação com o mundo. Assim, uma fratura na perna constitui primordialmente uma redução da possibilidade existencial de se aproximar ou de se afastar daquilo que se oferece ao nosso encontro no mundo, independentemente, aliás do fato dos sofrimentos provocados por uma fratura reduzirem consideravelmente a abertura para o mundo de um 'da-sein', não lhe deixando mais que um pequeno número de interesses (p. 30).

Boss \& Condrau (1997) citam outros exemplos na mesma linha do citado da fratura, agora no domínio da psicopatologia. Para compreender uma paralisia histérica, dizem eles, a Daseinsanalyse não precisa recorrer à "invenção de desejos insconscientes" [e aqui, como em alguns outros momentos deste artigo, os autores são explícitos em sua crítica a Freud]:

Sem que seja necessário recorrer a hipóteses metapsicológicas, qualquer paralisia histérica pode ser diretamente compreendida como uma perturbação que afeta a possibilidade de realizar na corporeidade uma certa relação com o que se apresenta no mundo, isto é, como uma perturbação que consiste em interdições estranhas à pessoa” (Boss, \& Condrau, 1997, p. 30).

No mesmo artigo os autores assinalam que o modo de ser-doente pela redução dos existenciais "disposição" "e o ser-aberto", relacionadas às distimias depressivas são cada vez mais freqüentes: "Hoje encontra-se cada vez mais pessoas sofrendo de uma opressão vaga, do absurdo e do tédio, de sua vida (...) Freqüentemente estes doentes tentam durante muito tempo mascarar seu desespero se entorpecendo, seja pelo trabalho, pelas distrações ou pelas drogas". (Boss \& Condrau 1997, p. 31).

Esta observação, ainda que se refira à realidade de pelo menos cerca de 40 anos atrás, parece muito característica da nossa sociedade contemporânea da epidemia da depressão (Moreira, 2002). Este distúrbio da abertura para mundo do Dasein é descrito por Boss \& Condrau (1997) como o tédio, em que o homem ainda que esteja aberto para o mundo enquanto ente, não o está como ser, ou seja, não deixa que lhe cheguem mensagens do mundo, não se deixa tocar, permanecendo fundamentalmente indiferentes a tudo. Para estas pessoas o tempo é comprido, o que quer dizer que no tédio é principalmente a temporalidade que é afetada, não existindo futuro verdadeiro ou passado rico de experiências, nem mesmo presente que tenha algum sentido.

Ainda que todos estes modos de ser-doente apresentem uma perturbação da realização do caráter fundamental do ser-humano que é seu ser-livremente-no-mundo, ao mesmo tempo em que lhe revela o mundo, para Boss \& Condrau (1997) a esquizofrenia deve ser considerado o modo de ser-doente mais humano e, ao mesmo tempo, mais desumano:

Justamente porque aqui se manifesta abertamente uma grave perturbação fundamental do ser humano, isto é, em seu ser-aberto esta doença mais do que qualquer outra coisa lança uma luz sobre a natureza mais profunda de nosso existir e por isso mesmo sobre sua fragilidade. A esquizofrenia pode ser considerada uma perturbação específica do 'poder-existir-o-ser-aberto' conforme a essência do ser-aí (p. 31).

Existiria no esquizofrênico uma dupla incapacidade: de poder se engajar totalmente no que se mostra na abertura do seu existir e de preservar seu si-mesmo capaz de manter uma relação livre com o que aparece.

O esquizofrênico perde sua liberdade existencial no momento em que como ser-aí, enquanto possibilidade de responder aos numerosos significados e às diversas solicitações do que aparece em seu mundo, se sobrecarrega a tal ponto que ele não é mais capaz de responder ao que aparece como o fazem todas as pessoas ao seu redor. Ele não é mais capaz de resistir à dissolução de seu ser na esfera de seu mundo tornado vasto demais (Boss \& Condrau 1997, p. 32).

Isto explicaria o fato deste modo de ser-doente aparecer, mais freqüentemente, na puberdade ou em mulheres depois da maternidade quando as exigências em relação ao outro se tornam mais fortes, para um "deixar aproximar-se" entre adultos do sexo oposto ou para o devotamento do amor materno. Boss \& Condrau (1997) 
defendem a idéia de que ninguém pode ser considerado esquizofrênico e que a esquizofrenia não pode ser considerada uma doença em si-mesma. Mais conveniente seria se perguntar:

Esquizofrênico diante de qual situação relacional acima de suas forças? (...) O caráter patológico destes doentes reside no fato de lhes faltar uma possibilidade de existir em relação aos seres sãos. Falta-lhes acentuadamente a capacidade de assumir as possibilidades constitutivas do seu ser-aí para tornar-se si-mesmo livre e autônomo cuja abertura para o mundo possa se manter firme face a tudo que a eles se oferece. (...) Assim, pode-se dizer que [os esquizofrênicos] existem em grande parte fora deles mesmos. São tão pouco capazes de assumir as suas possibilidades num sersi-mesmo autônomo que somente podem sentir o que se mostra a eles como algo estranho e imposto de fora. É por isso que tão freqüentemente têm a impressão de que o que a eles se oferece é ditado por ‘vozes' exteriores e que tudo o que fazem e pensam é pensado por outra pessoa (pp. 32-33).

Em outras palavras, as assim chamadas alucinações no esquizofrênico seriam fruto de uma total impossibilidade de ser-si-mesmo autônomo. Da mesma forma que nos esquizofrênicos, Boss \& Condrau (1997) vêem nos neuróticos obsessivos uma perturbação da liberdade existencial, de caráter defensivo tal como ocorre nas esquizoidias ou no autismo: "De fato, o que existe de mais oposto à liberdade do que a obsessão?” (p, 33). No entanto, os autores assinalam que a realização do ser-aberto e do ser-livre nos neuróticos obsessivos jamais será atingida da mesma maneira que nos esquizofrênicos; eles jamais são absorvidos completamente pelo percebido nem se perdem, enquanto ser-humano, totalmente nele como ocorre nos esquizofrênicos.

Na medida em que Boss desloca o entendimento da doença para a compreensão da experiência do ser-doente, considera, então, a psicopatologia como redução ou perda das possibilidades constitutivas dos modos do existir humano enquanto Dasein. Assim, no ser-doente por uma perturbação na corporalidade teremos, por exemplo, as doenças psicossomáticas ou a conversão histérica; na espacialidade teremos a agorofobia; no humor teremos a mania e a depressão, na realização do ser aberto teremos a esquizofrenia (Boss \& Condrau, 1997).

Ainda que Medard Boss seja considerado o autor na área da psiquiatria que se manteve mais próximo da proposta heideggeriana (Gonçalves, Garcia, Dantas \& Ewald, 2008), Loparic (2002) insiste no "fracasso da escola suíça" (referindo-se a Boss e a Binswanger) no que se refere à utilização apropriada da Analítica do Dasein de Heidegger pela psiquiatria. Para além desta discussão, é possível observar que as interessantes observações de Boss sobre os modos de ser-doente, com base nos existenciais de
Heidegger, carecem de maior profundidade e sistematização. Além disso, o pensamento de Heidegger é infinitamente mais amplo que os existenciais, aos quais Boss parece se aferrar. Neste sentido, mesmo tendo claro que mais pesquisas sobre este assunto necessitariam ser feitas, talvez seja possível arriscar dizer que Loparic (2002) tinha razão. Só que, no caso de Binswanger, se ele não conseguiu "se apropriar adequadamente" da Analítica do Dasein heideggeriana, acabou criando novas vertentes: a Análise Existencial e a Psicopatologia Fenomenológica. No caso de Boss, a questão parece mais complicada, merecendo pesquisas mais extensas que possam vir a esclarecer melhor esta questão.

\section{Arthur Tatossian: Uma Psicopatologia Contempo- rânea do Lebenswelt}

Arthur Tatossian (1929-1995) nasceu em Marseille, na França, filho de uma família de emigrantes armênios, o que segundo Jeanne Tatossian - sua esposa -, teve repercussões profundas na sua personalidade tímida e sempre discreta. Foi o que poderia ser chamada de "uma criança superdotada”, dormia poucas horas por noite e usava as outras horas para trabalhar (Tatossian \& Samuelian, 2006). De formação médica, dedicou-se a neurologia e, posteriormente a psiquiatria, sendo seus artigos mais profundos os fenomenológicos (Darcourt, 2006). Ao longo de sua carreira ocupou vários cargos, tanto na docência da psicopatologia, como de chefias de serviços médicos. Trabalhou no Hospital de Marseille em 1952 e em 1959 se tornou Chefe do Serviço de Neuropsiquiatria. Ocupou, ainda, vários outros cargos, entre os quais o de MédicoChefe da Rede de Hospitais de Marseille e encarregado do curso de Psicologia na Faculdade de Medicina de Marseille, em 1961.

Além de artigos e capítulos de livros deixou três publicações na França: Psychiatrie Phénomenologique, obra póstuma que reúne seus primeiros textos fenomenológicos praticamente desconhecidos visto que ele os publicava em revistas locais ou não os publicava; La vie en faute de mieux, um livro sobre a depressão, de linguagem menos acadêmica e mais acessível que, segundo Jeanne Tatossian$^{1}$, Arthur Tatossian não valorizava muito; e Phénomenologie des Psychoses, publicado em português pela Editora Escuta em 2006.

Mas, se Tatossian, após sua morte prematura aos 66 anos, não deixou mais que três livros publicados (que se superam em número pela densidade de seu texto), chama a atenção o número de pessoas - ex-alunos e colegas dele na universidade ou no Hospital de La Timone, onde dirigiu o Serviço de Psiquiatria e de Psicologia Médica a partir de 1980, além, é claro, de Jeanne Tatossian - que

\footnotetext{
Algumas das informações aqui relatadas como sendo de autoria de Mme Tatossian, esposa de Arthur Tatossian, foram relatadas em conversas informais quando da ida da autora em visita a Marseille, no outono de 2001.
} 
o admiravam em sua enorme sensibilidade humana, fato que pode ser observado nos prólogos e prefácios de seus livros, que não apenas mencionam a obra, mas o homem. Ele foi reconhecido não apenas pelo seu papel desempenhado no pensamento fenomenológico como na prática psiquiátrica do seu cotidiano clínico. Nunca quis ser considerado um mestre nem criar escolas, pois achava que a fenomenologia já se "vivia” e não poderia se resumir em receitas (Tatossian \& Samuelian, 2006). A possibilidade de reunir esta sensibilidade, juntamente com sua grande capacidade de trabalho (tinha o hábito de dormir quatro horas por noite, trabalhando durante as outras horas), além de sua reconhecida genialidade (vide, por exemplo, o fato de ter aprendido alemão sozinho a fim de ler os originais de Husserl, Heidegger e outros autores alemães para a sua tese de Doutorado em Medicina, de 1957, intitulada Étude Phénomenologique d'un cas de esquizophrenie paranöide, publicado postumamente no livro Psychiatrie Phénomenologique, em 1997, faz do pensamento de Arthur Tatossian uma psicopatologia fenomenológica da clínica - sua preocupação prioritária era a pessoa em sofrimento, o paciente; para a clínica - entendia que o que de mais útil a fenomenologia poderia oferecer à psiquiatria seria "uma comunicação compreensiva com o Outro" (Tatossian \& Samuelian, 2006, p. 354).

\subsection{Uma Psicopatologia Fenomenológica da Clínica e para a Clínica}

Um aspecto que salta aos olhos ao leitor da obra de Arthur Tatossian é a enorme facilidade com que ele passeia através das obras dos vários autores da fenomenologia: Husserl, Heidegger, Sartre, Merleau-Ponty, Scheler, bem como autores que contribuem diretamente para a tradição fenomenológica em psicopatologia: Jaspers, Binswanger, Minkowski, Blankenburg, Tellenbach, Von Gebsattel, Van Den Berg, Kimura, entre outros.

Seus escritos consistem em um constante diálogo com estes representantes da fenomenologia, o que faz de sua obra uma psicopatologia fenomenológica contemporânea, na medida em que integra em um só texto, em um momento histórico um pouco mais avançado - segunda metade do século XX até a atualidade - grandes nomes da fenomenologia. A partir deste diálogo crítico com alguns dos clássicos da psicopatologia fenomenológica, Tatossian escreve uma psicopatologia fenomenológica mais amadurecida, em que:

A fenomenologia utilizada em psiquiatria não é a banal aplicação de uma teoria filosófica, mas antes, uma forma de 'questionar' e de compreender o doente mental; que realiza uma fenomenologia que sabe distinguir sintoma de fenômeno e tomando consciência da importância do 'modo de ser-no-mundo' (...) não esquecendo que o doente é um ser que sofre e que o melhor a fazer é reconfortá-lo em vez de elaborar hipóteses, certamente muito sedutoras, mas pouco úteis na prática clínica cotidiana (Tatossian \& Samuelian, 2006, p. 354-355).

A preocupação em desenvolver uma psicopatologia da clínica e para a clínica é central no pensamento de Tatossian. Logo no início de Fenomenologia das Psicoses ele explicita sua posição:

Talvez o presente estudo se justifique por apresentar, sem pretensão de originalidade, mas com a preocupação da fidelidade a uma visão de conjunto a mais completa possível, o quadro da fenomenologia psiquiátrica tal como ela tem sido praticada pelos psiquiatras e não como poderia ou deveria sê-lo a partir de tal filosofia (Tatossian, 2006, p. 23).

E mais adiante:

Se ele [o psiquiatra] deseja atingir a experiência propriamente fenomenológica da doença mental, não pode se isolar com o filósofo transcendental em sua torre de marfim. Ao trabalho especulativo sobre a literatura especializada, que foi o método de MerleauPonty e de outros também, deve preferir obrigatoriamente o comércio direto com o que está em questão: a loucura e o louco (Tatossian, 2006, p. 29).

A preocupação primordial de Tatossian com a clínica leva-o a se posicionar criticamente em relação ao "quadrunvirato fenomenológico dos anos 1920” - Binswanger, Minkowski, Straus e Von Gebsattel -, criticando a Binswanger, um de seus constantes interlocutores, por suas habituais e, em sua opinião, excessivas exposições teóricas e análises com considerações metodológicas. Acreditava que Minkowski, Straus e Von Gebsattel permaneciam mais próximos da experiência clínica, o que também acontecia na psiquiatria mais recente, onde apesar da via seguida por Binswanger, seria a imbricação mais íntima entre metodologia e análise de casos clínicos que predominava (Tatossian, 2006).

Da mesma forma, Tatossian critica o que ele chama de "reviravolta fenomenológica" do pensamento de Binswanger que, havendo partido do Dasein de Heidegger para pensar a psicopatologia, como que retrocede à fenomenologia da consciência de Husserl. Referindo-se a obra de Binswanger, Melancolia e Mania, afirma: "A análise existencial de Heidegger permanece, sem dúvida, como o afirma no prefácio, o ponto de partida, mas se apaga no corpo do trabalho diante da fenomenologia de Husserl, sob a sua forma mais técnica" (Tatossian, 2006, p. 172). Para Tatossian, distanciar-se do Dasein como horizonte metodológico da clínica, traz graves e profundas implicações, dado que significa perder de vista a idéia dos estados psíquicos enquanto transformação da estrutura onto- 
lógica primordial do ser-no-mundo, independente de um modo de ser patológico. Na fenomenologia transcendental, os estados psíquicos estariam explicitamente presentes enquanto doença mental em sua constituição:

A passagem da Daseinsanalyse à fenomenologia transcendental comporta, assim, ir de uma atitude profundamente impregnada pela historicidade humana a uma outra totalmente a-histórica e, mais grave, de uma perspectiva que, com Heidegger, teria superado a distinção sujeito/objeto a uma outra que não a supera mais, já que fala de doenças. A solução é sem dúvida que a perspectiva da fenomenologia não exclui aquela da Daseinsanalyse (Tatossian, 2006, p. 173).

Ou seja, trata-se de pensar em termos de uma complementaridade entre as propostas de Husserl e de Heidegger para se pensar a psicopatologia.

\subsection{O Lebenswelt como Foco na Psicopatologia Feno- menológica Contemporânea}

Tatossian (2006) entende que o último Husserl quis mostrar a capacidade da fenomenologia de incorporar a existência e o que havia sido colocado por Heidegger em Ser e Tempo. Para isto desenvolveu mais amplamente o conceito de Lebenswelt que, por sua vez irá, posteriormente, caracterizar a fenomenologia existencial de MerleauPonty "e que interessa à psicopatologia fenomenológica em sua referência simultânea a Husserl e Heidegger" (p. 87). Merleau-Ponty, um representante contemporâneo do pensamento fenomenológico, tem o conceito de Lebenswelt como fio condutor de todo o seu pensamento ambíguo (Bidney, 1989).

Para além de uma complementaridade da Fenomenologia e da Daseinsanalyse, defendida por Kuhn, Tatossian (2006) vai, então, preferir a pista deixada por Husserl e desenvolvida por Merleau-Ponty: o Lebenswelt. Cita a Bröekman para quem a análise heideggeriana seria uma análise do Lebenswelt e a Merleau-Ponty, em Fenomenologia da Percepção quando este afirma que tudo em Heidegger havia partido de uma indicação de Husserl, o Lebenswelt. Com base no desenvolvimento deste conceito é que Tatossian justifica a "reviravolta" de Binswanger à fenomenologia husserliana: "É por isso que a fenomenologia psiquiátrica atual, impulsionada pelo próprio Binswanger se orientou em direção a Husserl em sua obra tardia...” (p. 85).

Segundo Tatossian (2006), o Lebenswelt, tal como conceituado nos textos do último Husserl - da Experiência e Julgamento e da Krisis - significa uma realidade primária da nossa experiência imediata, o mundo das significações tal como ele se apresenta à ação humana. Este mundo é, antes de tudo, o mundo do indivíduo humano, ou seja, é o segmento da existência humana vivida pelo indivíduo em sua unicidade sendo, assim, o lugar da vida primária do indivíduo, caracterizado essencialmente por sua familiaridade - o meu mundo - um horizonte interno da experiência. "Os conteúdos podem variar de uma sociedade a outra e neste sentido há os Lebenswelten, mas a forma do Lebenswelt é única (...) É porque 'meu'mundo é sempre assim 'nosso'mundo, um mundo intersubjetivo, um mundo comum" (Tatossian, 2006, p. 88).

O Lebenswelt, aqui, é ainda o mundo correlativo do mundo natural, mas agora no nível da experiência préintencional, não mais no nível intencional e conceitual tal como descrito no jovem Husserl. O Husserl tardio revela as estruturas pré-predicativas da experiência:

O Lebenswelt é o mundo percebido por baixo das construções do pensamento. O eidos está presente aqui, mas não como essência fechada, inata e fixada, mas como estrutura de sentido aberta, histórica e, portanto, de validade forçosamente transitória, assintótica da experiência humana vivida (Tatossian, 2006, p. 88-89).

Neste sentido, na medida em que se encontra no domínio do pré-reflexivo, não cabe a distinção entre consciente e inconsciente. Para Tatossian (2006), a psicopatologia deve visar o Lebenswelt do doente em duas dimensões de sua experiência: por um lado trata-se de uma experiência pré-teórica e pré-objetiva que temos diante do doente e, por outro, parte da questão de como se constitui um Lebenswelt particular que se imprime sobre seu vivido, sua experiência, sua ação, sua forma de se apresentar no mundo. O Lebenswelt

(...) existe como mundo concreto e cotidiano, é sempre individual, é sempre 'meu'mundo, sendo também totalmente 'nosso' mundo porque [é] impregnado de historicidade e intersubjetividade (...) o Lebenswelt não pode ser compreendido como pura derrelição e implica a entrada em cena da estrutura de projeto de ser humano" (Tatossian, 2006, p. 207).

\subsection{O Tempo Vivido}

O conceito de Lebenswelt é utilizado ao longo da Fenomenologia das Psicoses, seja na descrição e compreensão das diferentes enfermidades, seja no diálogo com outros autores da psicopatologia fenomenológica. Diretamente ligada ao vivido no Lebenswelt é que a questão da temporalidade ocupou um lugar de destaque no pensamento de Tatossian, sem que com isso ele se descolasse das outras dimensões do vivido humano tal como espacialidade, corporalidade, abertura ao mundo e assim por diante.

A temporalidade esteve intimamente relacionada a sua própria clínica, onde Tatossian deu especial aten- 
ção a esta questão, sempre muito atento à forma como o tempo era vivenciado por seus pacientes. Este tema amplamente desenvolvido em Binswanger, Minkowski e Tellenbach - fez com que ele estivesse em constante diálogo com estes autores. O tempo vivido, seja para o indivíduo doente ou sadio, não é o tempo mensurável, que pode ser medido objetivamente - "o tempo do mundo exterior ao sujeito" -, mas é o tempo imanente ao sujeito, o tempo dele. Para Tatossian (2006), os indivíduos "normais" tem o tempo dominado pela noção de devir, de futuro, enquanto que o indivíduo doente vivencia alterações no tempo vivido: o melancólico, por exemplo, vive, passivamente, uma estagnação do tempo pela inibição do devir e a impossibilidade de antecipações, ficando preso ao passado; o maníaco também vivencia esta mesma estagnação embora ativamente, como que querendo antecipar o futuro, e assim por diante.

O tempo vivido é o tempo do Lebenswelt: imanente e transcendente, consciente e inconsciente, singular e universal. E, nesse sentido, é fundamento de um modo de ser-no-mundo sadio ou patológico:

No homem normal o primado do futuro faz do vivido temporal um vivido de poder - poder de transformar o mundo pela ação, e a si mesmo pelo alargamento da pessoa. A imobilização do tempo vivido tem por corolário a perda da categoria do possível - não como possibilidade lógica, vazia, mas como possibilidade concretamente 'minha', como capacidade (p. 127).

Segundo Tatossian \& Samuelian (2006) a significação particular que Tatossian dá ao tempo vivido permite compreender sua tolerância e paciência em relação aos outros, o que repercutiu na sua qualidade de relação com seus pacientes. Para ele:

(...) o tempo é a escola da experiência, experiência do fenômeno. A identidade do sujeito não é mais que o equilíbrio entre identidade do eu e identidade do papel; é, portanto, um equilíbrio entre a constituição do outro por si e a constituição de si pelo outro. Se esse equilíbrio não é atingido, ou se subitamente é posto em dúvida, a vida cotidiana não pode ser vivida senão como uma impostura evidente, e os distúrbios do comportamento aparecem (...) É, portanto, nesta situação paradoxal em que se encontra colocado o sujeito que ele deve construir o mundo fora dele, que lhe é ao mesmo tempo imanente e transcendente (Tatossian, 2006, p. 356).

É neste sentido que a psicopatologia fenomenológica de Arthur Tatossian não é uma explicação, mas um "ver" da experiência psiquiátrica, sendo em si empírica e apriórica. A contribuição singular do pensamento de Arthur Tatossian tem um duplo sentido: aliado ao fato de, por se encontrar em um momento histórico posterior, Tatossian ter tido a possibilidade de construir seu pensamento no diálogo com os autores clássicos da fenomenologia da primeira metade do século XX, ele atualiza esta vertente na medida em que procura desenvolver seu pensamento em torno do conceito de Lebenswelt. Cria-se com Tatossian uma psicopatologia fenomenológica contemporânea.

\section{Considerações Finais}

A psicopatologia fenomenológica não pode se dar de outra forma que não seja a existencial. É impossível uma psicopatologia fenomenológica transcendental, pois esta não é uma ciência natural, que pode ter um método eidético transcendental puro, tal como era o projeto do primeiro Husserl, mas uma ciência do empírico, do outro, do ser-no-mundo, ou do Lebenswelt. Como bem lembra Merleau-Ponty, no prefácio da "Fenomenologia da Percepção": a essência está na existência. Este é o eixo central que, de alguma maneira, atravessa o pensamento de cada um destes quatro grandes nomes da psicopatologia fenomenológica.

Karl Jaspers, ao introduzir o método fenomenológico em seu trabalho de descrever e compreender uma psicopatologia geral inaugura uma nova área do saber - a psicopatologia - que a partir de então se preocupará tanto com a realidade subjetiva quanto com a realidade objetiva de pessoas que sofrem com transtornos mentais. Ludwig Binswanger, com sua daseinsanalyse, que passou a se chamar análise existencial, inaugura a tradição da psicopatologia fenomenológica, cuja preocupação primordial não é mais o psíquico ou a doença, mas o homem. Medard Boss desenvolve, ou pelo menos dá os primeiros passos, na direção de uma psicopatologia mais puramente inspirada no Dasein de Heidegger. Finalmente, Artur Tatossian, a partir do diálogo com os filósofos e psiquiatras representantes da tradição fenomenológica em psiquiatria, descreve uma psicopatologia fenomenológica contemporânea do Lebenswelt.

Quatro grandes nomes, quatro contribuições singulares à psicopatologia fenomenológica existencial.

\section{Referências}

Bauchesne, H. (1993). Histoire de la Psychopathologie. Paris, PUF.

Bidney, D. (1989). Phenomenological Method and the Anthropological Science of the Cultural-Life. Em M. Natanson, Phenomenology and the Social Sciences. Evanston, Northwestern University Press.

Binswanger, L. (1970). Analyse existencielle et psychanalyse freudienne. Paris: Gallimard.

Binswanger, L. (1971a). Introduction. Em L. Binswanger, Introduction à l'analyse existentielle [pp. 39-47]. Paris : Les Éditions de Minuit. 
Binswanger, L. (1971b). Fonction Vitale et histoire intérieure de la vie. Em L. Binswanger, Introduction à l'analyse existentielle [pp. 49-77]. Paris: Les Éditions de Minuit.

Binswanger, L. (1971c). Analyse de la Phenomenologie. Em L. Binswanger, Introduction à l'analyse existentielle [pp. 79117]. Paris: Les Éditions de Minuit.

Binswanger, Ludwig (1971d). Analyse Existentielle et Psychotherapie. In L. Binswanger, Introduction à l'analyse existentielle (pp. 149-157). Paris, Les Éditions de Minuit.

Binswanger, L. (1977). El caso de Ellen West: estudio antropológico-clínico. Em Rollo May, E. Angel, \& H. Ellenberger (Eds). Existencia [pp. 288-434]. Madrid: Gredos.

Boss, M. (1976). Solidão e comunidade. Daseinsanalyse - Revista da Associação Brasileira de Daseinsanalyse, 2, 25-45.

Boss, M. (1997). Encontro com Boss. Daseinsanalyse - Revista da Associação Brasileira de Daseinsanalyse, 2, 5-21.

Boss, M. \& Condrau, G. (1997). Daseisanalyse: como a Daseinsanalise entrou na psiquiatria. Daseinsanalyse - Revista da Associação Brasileira de Daseinsanalyse, 2, 23-35.

Cunha, A. (1997). Dicionário Etimológico Nova Fronteira. Rio de Janeiro, Nova Fronteira.

Darcourt, G. (2006). Prefácio à segunda edição francesa. Em Arthur Tatossian, Fenomenologia das Psicoses [pp. 19-22]. São Paulo: Escuta.

Fédida, P. (1998). De uma psicopatologia geral a uma psicopatologia fundamental. Nota sobre a noção de paradigma. Revista Latinoamericana de Psicopatologia Fundamental, 1 (3), 107-121.

Freire, J.C. (2008). O lugar do outro na daseinsanalyse de Binswanger. Estudos e Pesquisas em Psicologia (UERJ), 8(2), 261-271.

Gonçalves, R., Garcia, F., Dantas, J. \& Ewald, A. (2008). MerleauPonty, Sartre e Heidegger: três concepções de fenomenologia, três grandes filósofos. Estudos e Pesquisas em Psicologia (UERJ), 8 (2), 396-346.

Heidegger, M. (1989). Ser e Tempo. Petrópolis: Vozes.

Heidegger, M. (2001). Seminários de Zollikon. Petrópolis: Vozes.

Jaspers, K. (1987). Psicopatologia geral. Rio de Janeiro: Atheneu (Original publicado em 1913).

Jaspers, K. (2005). A abordagem fenomenológica em psicopatologia. Revista Latinoamericana de Psicopatologia Fundamental, 8 (4), 769-787 (Original publicado em 1912).

Kuhn, R. \& Maldiney, H. (1971). Préface. Em L. Binswanger, Introduction à l'analyse existentielle [pp. 7-24]. Paris: Les Éditions de Minuit.
Loparic, Z. (2002). A semântica transcendental de Kant. Campinas: Unicamp.

Mattar, C. M. \& Novaes de Sá, R. (2008). Os sentidos de "análise" e "analítica" no pensamento de Heidegger e suas implicações para a psicoterapia. Estudos e Pesquisas em Psicologia (UERJ), 8 (2), 189-200.

May, R. (1988). A descoberta do ser. Rio de Janeiro: Rocco.

Moreira, V. (2002). Psicopatologia crítica. In V. Moreira \& T. Sloan. Personalidade, ideologia e psicopatologia crítica [pp. 109-248]. São Paulo, Escuta.

Moreira, V. (2010). Possíveis contribuições de Husserl e Heidegger para a clínica fenomenológica. Psicologia em Estudo (Maringá), 15(4), 723-731.

Pereira, M. (2001). Sobre os fundamentos da psicoterapia de base analítico-existencial, segundo Ludwig Binswanger. Revista Latinoamericana de Psicopatologia Fundamental, 4 (1), 137-142.

Rodrigues, A. C. T. (2005). Karl Jaspers e a abordagem fenomenológica em psicopatologia. Revista Latinoamericana de Psicopatologia Fundamental, 8 (4), 754-768.

Tatossian, A. (2006). Fenomenologia das psicoses. São Paulo: Escuta.

Tatossian, J. \& Samuelian, J.-C. (2006). Pósfacio da segunda edição francesa. Em Arthur Tatossian. Fenomenologia das Psicoses [pp. 347-357]. São Paulo: Escuta.

Van den Berg, J. H. (1994). O paciente psiquiátrico esboço de uma psicopatologia fenomenológica. Campinas: Editorial Psy.

Verdeaux, J. \& Kuhn, R. (1971). Glossaire. Em L. Binswanger. Introduction à l'analyse existentielle [pp. 27-37]. Paris : Les Éditions de Minuit.

Widlöcher, D. (1996). Les nouvelles cartes de la psychanalyse. Paris: Odile Jacob.

Virginia Moreira - Psicoterapeuta, Doutora em Psicologia Clínica pela Pontifícia Universidade Católica de São Paulo e Pós-Doutora em Antropologia Médica pela Harvard University. É Professora Titular da Universidade de Fortaleza e Affiliated Faculty da Harvard Medical School. Endereço para correspondência: APHETO - Laboratório de Psicopatologia e Psicoterapia Humanista Fenomenológica Crítica. Programa de Pós-Graduação em Psicologia, Universidade de Fortaleza. Av. Washington Soares, $\mathrm{n}^{0} 1321$ - Fortaleza, Ceará, Brasil. E-mail: virginiamoreira@unifor.br; virginia_moreira@hms.harvard.edu

Recebido em 30.03.2011

Aceito em 25.07.2011 